\title{
Injection Strategies for Isobaric Combustion
}

\author{
Rafig Babayev, Moez Ben Houidi, VS Bhavani Shankar, Bassam Aljohani, Bengt \\ Johansson
}

\begin{abstract}
Clean Combustion Research Center (CCRC), King Abdullah University of Science and Technology (KAUST),
\end{abstract} Thuwal 23955-6900, Saudi Arabia

\begin{abstract}
In a previous study, we demonstrated that the isobaric combustion cycle, achieved with a split injection strategy, can be more suitable for the double compression expansion engine concept than the conventional diesel combustion cycle. The present work is focused on understanding the effect of different injection strategies on the heat release, efficiency, and emissions of isobaric combustion at the peak cylinder pressure of 150 bar. In situ injection rate measurements are performed to improve our understanding of the heat release rate shape and pollutant formation. A variation of load is performed to demonstrate the feasibility of the isobaric combustion cycle at higher loads, and the means of achieving them. The thermal efficiency reduces at lower loads because of heat losses. It peaks at a medium load point before reducing again at higher loads because of exhaust losses. The effect of altering the injection strategy on the isobaric combustion cycle is also studied at a constant equivalence ratio. The alteration of injection strategy is proven to have minimal effect on efficiency, loss mechanisms, and emissions when more than one injection is used.
\end{abstract}

\section{INTRODUCTION}

The double compression expansion engine (DCEE) concept utilizes a two-stage compression and expansion cycle to achieve very high efficiencies [1-2]. The effective utilization of unexpanded exhaust gases using a volumetric expansion machine and reduction in friction loss due to the extreme downsizing are the main reasons of this improvement. 1-D modelling studies have hinted the benefits of isobaric heat addition for the DCEE concept [2-4]. It was shown by Okamoto and Uchida [5] that achieving cycles approaching isobaric is possible using three separate injectors.

In our previous experimental study [6], the possibility of isobaric heat addition was demonstrated using a conventional single-injector system using multiple main injections. It was demonstrated that isobaric combustion cycle is capable of achieving thermal efficiencies equal or greater than those of the conventional diesel combustion (CDC) cycle at the same peak cylinder pressures (PCP). This study revealed a reduced wall heat transfer with only a marginal penalty on gross work compared to conventional diesel combustion. The reduction in heat loss was translated to greater exhaust energy which could be put to effective use in a multiple expansion device. Thus, the isobaric combustion cycle might be even more advantageous for the DCEE concept as the increased exhaust energy can be recovered in the second expansion stage. Moreover, it was shown that isobaric combustion can also enable a reduction in NOx emissions by a factor of two compared to the CDC cycle without a penalty on the soot emissions at low EGR rates. At high EGR rates, isobaric combustion is capable of achieving comparable efficiency values, and substantial improvements in NOx emissions compared to the CDC cycle, while operating at significantly lower PCPs. This suggested additional benefits in terms of friction losses.

Relatively recent developments in common rail highpressure injection systems made possible multiple injections per cycle. Up to ten injections per cycle are possible with both piezoelectric and solenoid valve technologies. This advancement made possible the split injection strategies in $\mathrm{Cl}$ engines and have many benefits for emission and noise reduction [7-11].

One of the challenges associated with isobaric combustion cycle is the need for multiple injections with relatively short delay between the successive injections. This is requires a fine control of the shape of heat release. In the previous work, a solenoid injector was used to achieve the isobaric combustion. The solenoid valve injectors have relatively low needle speeds, thus very short separations between injections required to achieve isobaric combustion cycle led to instabilities in the fuel injection system [6]. Moreover, most modern injection systems are designed for only one main injection event along with several pilot or post injections to help reduce the NOx and soot emissions. The effect of using multiple main injections 
with short shot-to-shot separations on the injection system stability and wear has not been explored yet. Taking the aforementioned issues into account, it is necessary to study a number of alternative injection strategies that lead to cycles close to isobaric, which is one of the targets of this paper.

To enhance our understanding of the split injection strategies needed for isobaric combustion, the spray momentum analysis is performed in the present work using an in-situ technique. The injection rate was estimated for all studied cases which helped to better understand the trends in the heat release rate and the pollutants formation.

It is also necessary to investigate the effect of different load conditions on the isobaric combustion cycle, as well as the means of achieving them. Simply increasing the injection duration to achieve higher engine loads is not feasible under the constraints of an isobaric heat addition [6]. This paper also presents a strategy that can be employed to achieve different engine loads.

The following two studies are performed at 150 bar PCP:

1. Variation of load $(1.3-20$ bar IMEPg) by increasing the number of injections (1-5) and their duration, when needed.

2. Variation of the number of injections (1-4) at a constant medium load (11.2 bar IMEPg).

The analysis is focused on the heat release rate shape, efficiency and emissions.

\section{EXPERIMENTAL SETUP}

\section{ENGINE TEST BENCH}

The experiments were performed on the KAUST-Volvo single cylinder research engine. A Volvo D13C500 6cylinder engine was modified by deactivating the valves of five out of six cylinders and disconnecting the cylinders from the intake and exhaust systems. The schematic of the experimental setup is shown in Figure 1. The test cell is connected to a high-pressure air compressor, and a pressure regulator is used on the intake line to control the flow feeding the engine. The intake and back pressure valves are controlled independently. The back pressure in all the experiments is set to a value higher than the intake pressure to simulate a pressure drop typical of that in a turbocharger. The engine specifications are listed in Table 1.

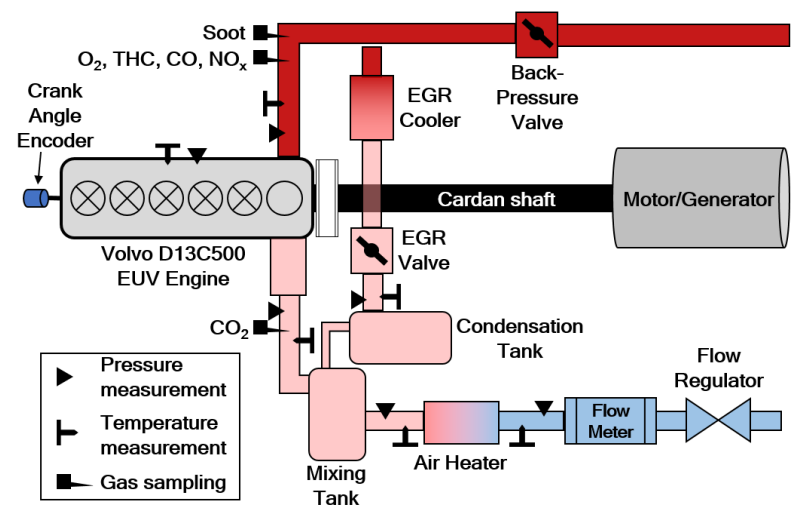

Figure 1. Schematic of the research test cell.

Table 1. Engine specifications.

\begin{tabular}{|l|l|}
\hline Base Engine Configuration & Single cylinder / 4 stroke \\
\hline Displacement Volume & $2.13 \mathrm{~L}$ \\
\hline Stroke & $158 \mathrm{~mm}$ \\
\hline Bore & $131 \mathrm{~mm}$ \\
\hline Connecting Rod & $255 \mathrm{~mm}$ \\
\hline Compression ratio & $17: 1$ \\
\hline Cam / Valve Configuration & $\begin{array}{l}\text { SOHC / 4 valves per } \\
\text { cylinder }\end{array}$ \\
\hline Fuel Injection System & $\begin{array}{l}\text { Delphi F2E Common Rail } \\
\text { (maximum pressure 2700 } \\
\text { bar) }\end{array}$ \\
\hline
\end{tabular}

\section{EMISSIONS MEASUREMENT}

The oxygen (O2), carbon monoxide (CO), carbon dioxide (CO2), unburned hydrocarbons (UHC), and nitrogen oxides (NOx) concentration in the exhaust gas is measured using a HORIBA MEXA-ONE-RS Motor Exhaust Gas Analyzer. The range of each measurement component depends on the span gases concentration, which are reported below:

- $\mathrm{CO}-4960 \mathrm{ppm}$

- $\quad$ CO2 - 18.45 vol\%

- $\mathrm{O} 2-20.00$ vol\%

- $\mathrm{CH} 4-977 \mathrm{ppm}$

- $\mathrm{NO}-8200 \mathrm{ppm}$

The soot emissions are measured using an AVL Micro Soot Sensor.

\section{INJECTION RATE MEASUREMENT}

It was necessary to characterize the injector in terms of the injection rate to gain a better understanding of the heat release rate shape and pollutants formation mechanisms. A spray momentum test-bed was built to measure the fuel mass flow rate of the split injection strategies used in this study. The injector was characterized in an optical version of the same 
D13C500 engine. In this configuration, the cylinder head is lifted to allow the installation of a piston extender, liner and window holder. After dismounting all of these parts, a special container was installed under the cylinder head, covering the injector nozzle without interfering with the valves. This container has a hole on the side for an AVL GU22C pressure sensor. The sensor was installed perpendicularly to the direction of the spray at a distance of $5 \mathrm{~mm}$ from one of the holes of the nozzle. The setup is illustrated in Figure 2.

The injector current and force signal are measured with $0.2 \mathrm{CAD}$ resolution through the main control and acquisition unit of the engine test-bench. In addition, a National Instruments PCl-6036 and a BNC-2110 are triggered by the control system to perform a parallel time resolved acquisition at $200 \mathrm{kHz}$. This installation allows to increase the sampling frequency while keeping the possibility to convert easily from one scale to another.

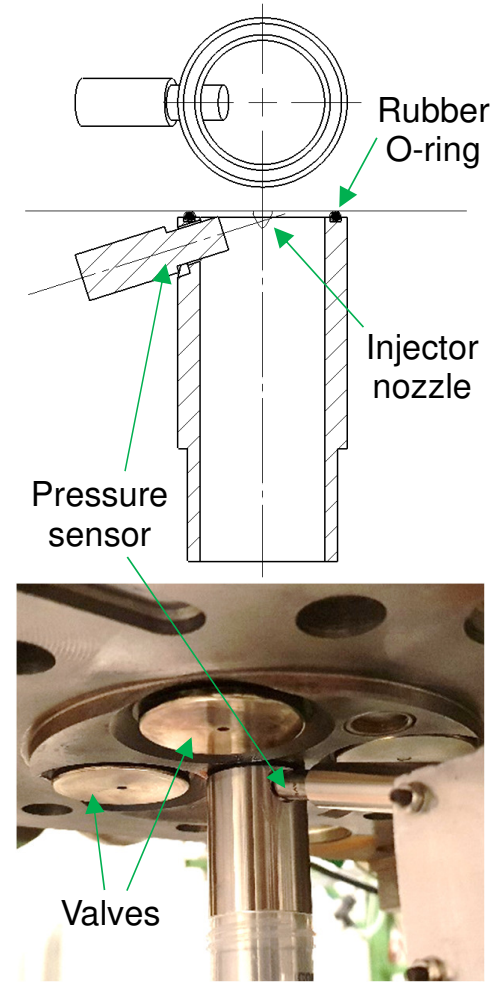

Figure 2. Injection rate measurement setup.

The pressure sensor in this setup is used as a force sensor and it has a natural frequency of $100 \mathrm{kHz}$. Thus, the recorded signal is low-pass filtered at $90 \mathrm{kHz}$. Then the signal is pegged and a compensation for the charge leakage is applied. Finally, the signal is averaged over 30 cycles. Based on the conservation of momentum, the mass flow rate can be calculated using Eq. 1 [12-13].

$$
\dot{\boldsymbol{m}}_{\boldsymbol{f}}=\sqrt{\boldsymbol{F} \rho_{f} A_{h}}
$$

$\boldsymbol{A}_{\mathrm{h}}-$ Cross-sectional area of the hole.

The injection rate is then proportional to the force generated by the projected liquid fuel on the sensor during the injection (Eq. 2).

$$
\dot{\boldsymbol{m}}_{\boldsymbol{f}}^{*} \sim \sqrt{\boldsymbol{F}}
$$

where, $\quad \dot{\boldsymbol{m}}_{\boldsymbol{f}}^{*}-$ Non-calibrated fuel mass flow rate.

The measured total mass of fuel injected per cycle in $\mathrm{mg}$ is then divided by the integrated non-calibrated mass flow rate obtained from the aforementioned procedure to find a calibration factor (Eq. 3).

$$
\alpha_{C}=\frac{m_{f}}{\int \dot{m}_{f}^{*} d(d e g)}
$$

Then, the non-calibrated mass flow rate is converted into a mass flow rate in $\mathrm{mg} / \mathrm{CAD}$ by multiplying it by the calibration factor (Eq. 4).

$$
\dot{m}_{f}=\alpha_{C} \times \dot{m}_{f}^{*}
$$

where, $\quad \dot{\boldsymbol{m}}_{\boldsymbol{f}}-$ Calibrated fuel mass flow rate.

It is known that the crank angle speed of 1200 RPM corresponds to $7.2 \mathrm{CAD} / \mathrm{ms}$. Consequently, in order to get the mass flow rate in $\mathrm{mg} / \mathrm{ms}$ it can be divided by 7.2 .

\section{DELAY IN THE INJECTION RATE MEASUREMENT}

Since the pressure sensor membrane is located $5 \mathrm{~mm}$ away from the nozzle hole it is necessary to account for the time required for the spray plume to reach the membrane. First, Eq. 5 is used to calculate the spray plume velocity.

$$
v=\frac{\dot{m}_{f}}{N_{h} \rho_{f} A_{h} C_{d}}
$$

where, $\boldsymbol{N}_{\boldsymbol{h}}-$ Number of holes in the injector nozzle,

$\boldsymbol{C}_{\boldsymbol{d}}$ - Discharge coefficient.

In this analysis the discharge coefficient is assumed equal to 0.9 , which is a typical value for high pressure diesel fuel injectors [14].

Then, the velocity in $\mathrm{m} / \mathrm{CAD}$ is integrated and plotted as a function of the crank angle. The resultant Figure $\underline{3}$ illustrates how long (in CAD) it takes for the spray plume to travel a certain distance.

where, $\boldsymbol{F}$ - Measured force,

$\boldsymbol{\rho}_{f}-$ Density of the fuel, 


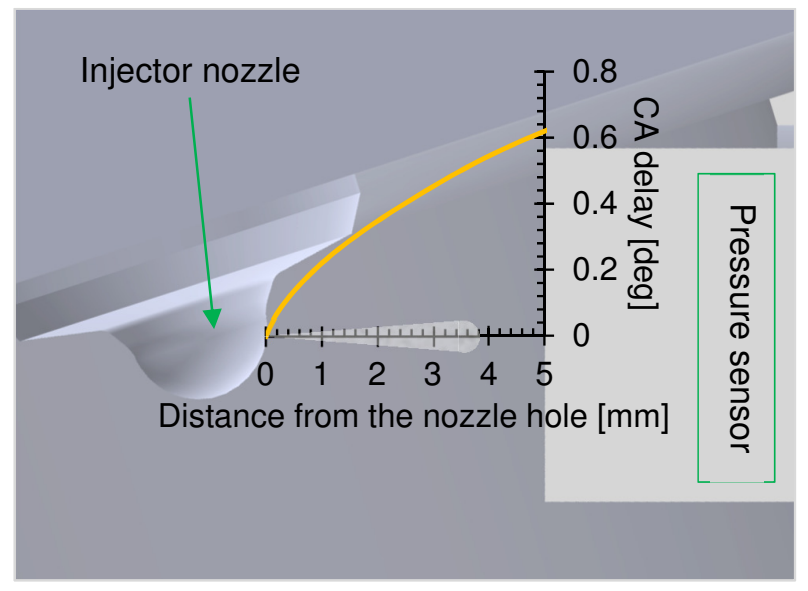

Figure 3. Estimation of the delay in the mass flow-rate signal based on the continuity equation for mass.

It should be noted that the injection rate undergoes a gradual increase as the injector needle is lifted. As can be seen from Figure 3 , this results in the injection velocity rise during the initial part of injection.

From Figure 3 it can be seen that it takes approximately $0.6 \mathrm{CAD}$ for the spray plume to travel $5 \mathrm{~mm}$ and reach the sensor membrane. Thus, in order to compensate for this delay, all spray rate profiles are shifted by 0.6 CAD earlier in the cycle. The analysis described above assumes negligible drag and gravity effects on the spray within the $5 \mathrm{~mm}$ gap between the nozzle hole and the sensor. Also, the discharge coefficient is assumed constant during the injection.

The results of the injection rate measurements are presented in the "Results and Discussion" section, under the "Injection Rate" subsection.

\section{1-D MODELING USING GT-POWER}

A 1-D gas-exchange model is set up in GT-Power Engine Simulation Software to estimate the cylinder temperature in order to get the best possible estimate of the exhaust losses. A "Measured-Pressure Analysis" option is utilized to estimate the burn-rate which is subsequently imposed in the forward run. A detailed description of the model and the associated parameters is available in the GT manual [15]. The actual averaged pressure and temperature measurements in the inlet and exhaust ports are imposed in the model. Heat transfer is estimated using the "WoschniGT" model. The convention heat multiplier is adjusted to attain the best possible match between the simulated pressure and the measured pressure data, as seen in Figure 4. The simulated temperatures are presented in later sections. The heat transfer flux is given in Appendix A.

It should be emphasized that the analysis is performed with a cycle-average pressure and temperature data from the inlet and exhaust ports rather than crankangle resolved. Hence, only the closed-system part of the cycle is modeled with high accuracy. This data is sufficient for the purposes of this study since only the mass-averaged temperatures after the inlet valve closing and before the exhaust valve opening are used in the later steps.

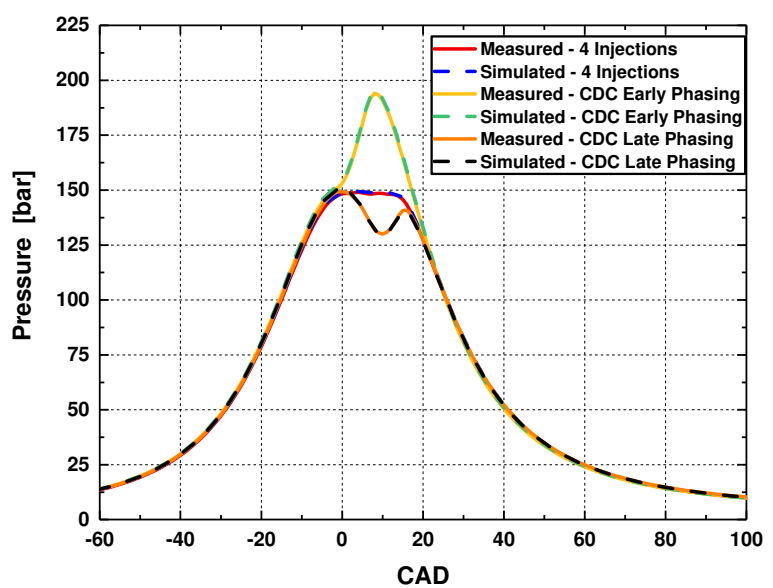

Figure 4. An example of the measured and simulated cycles shows a close agreement between them.

\section{ENERGY DISTRIBUTION CALCULATIONS}

The temperature estimated with 1-D modeling is used to estimate the exhaust energy according to Eq. 6 [16]:

$$
\begin{aligned}
& \Delta u_{\text {exh }}=m_{c} \times\left(c_{v(\text { exh. gas } @ T-E V O)} \times T_{E V O}-\right. \\
& \left.c_{v(\text { int. gas } @ T-\text { isochor. })} \times T_{\text {isochor. }}\right)- \\
& W_{(E V O \rightarrow B D C \& B D C \rightarrow \text { isochor. })}
\end{aligned}
$$

where, $\boldsymbol{\Delta} \boldsymbol{u}_{\boldsymbol{e x h}}$ - Internal energy of the exhaust gas,

$\boldsymbol{m}_{\boldsymbol{c}}$ - Mass of the exhaust gas,

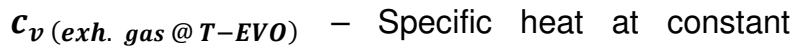
volume of the gas at the mass-averaged temperature just before the exhaust valve opening,

$\boldsymbol{c}_{\boldsymbol{v} \text { (int. gas } @ T \text {-isochor.) }}$ - Specific heat at constant volume of the intake gas at the temperature taken at the point in the compression stroke corresponding isochorically to the EVO.

$\boldsymbol{T}_{\boldsymbol{E V O}}$ - Mass-averaged temperature at the EVO,

$\boldsymbol{T}_{\text {isochor. }}$ - Mass-averaged temperature at the crank angle in the compression stroke corresponding isochorically to the EVO,

$\boldsymbol{W}_{(\boldsymbol{E V O} \rightarrow \boldsymbol{B D C} \boldsymbol{C} \& \boldsymbol{B D C} \rightarrow \text { isochor })}-$ Work produced between the crank angle of the EVO and the corresponding crank angle in the compression stroke at iso-volume.

The calculated internal energy represents the gasses that leave the cylinder not fully expanded. Then, the heat transfer losses can be estimated by performing the energy balance as per Eq. 7 . 


$$
\begin{gathered}
\text { HT Loss = Fuel Energy }- \text { Comb. Loss } \\
-\Delta u_{e x h}-\text { GI Work }
\end{gathered}
$$

where, HT Loss - Amount of energy lost to the walls via convection and radiation,

Fuel Energy - Total energy chemically bound in the fuel,

Comb.Loss - Amount of energy lost due to incomplete combustion,

GI Work - Gross indicated work calculated by integrating the pressure trace with respect to volume over the compression and expansion strokes.

\section{RESEARCH APPROACH}

The experiments are performed at a constant compression pressure of 150 bar. This means the intake air pressure is kept nearly constant for all the test points. The air-fuel equivalence ratio hence decreases when increasing load. The intake temperature and the common rail pressure in all experiments is set at $80^{\circ} \mathrm{C}$ and 2300 bar, respectively. No external EGR is used in this work.

The first study "Isobaric Combustion at Different Engine Loads" is conducted to investigate:

- Injection strategies necessary to achieve different engine loads

- Efficiency and the trade-offs in the loss mechanisms

- Dynamics of emissions formation and the total specific emissions at different loads

The second study "Effect of Injection Strategy" is performed to understand the effect of reducing the complexity in injection strategy on efficiency, loss mechanisms, and emissions.

The details of the test conditions for the two studies are presented in the next section under the "Isobaric Combustion at Different Engine Loads" and the "Effect of Injection Strategy" subsections.

\section{RESULTS AND DISCUSSION}

\section{INJECTION RATE}

In the "Experimental Setup" section we discussed the issue of the delay between the actual injection and the measured injection rate. This delay was compensated for by offsetting the signal based on the simple injection velocity estimation discussed previously. Figure 5 shows the rate of heat release and the injection rate as a function of crank angle. A dip in the RoHR between -1.5 CAD and -0.5 CAD ATDC can be observed in the figure. The negative RoHR is induced by the evaporation of the injected fuel. Figure 5 also shows the injection rate before and after the application of an offset of 0.6 CAD as per previous discussion. As a result of this adjustment, the injection trace starts approximately at the same time as the dip in the RoHR trace. This demonstrates that the implemented strategy is able to accurately estimate the delay in the measured signal and compensate for it.

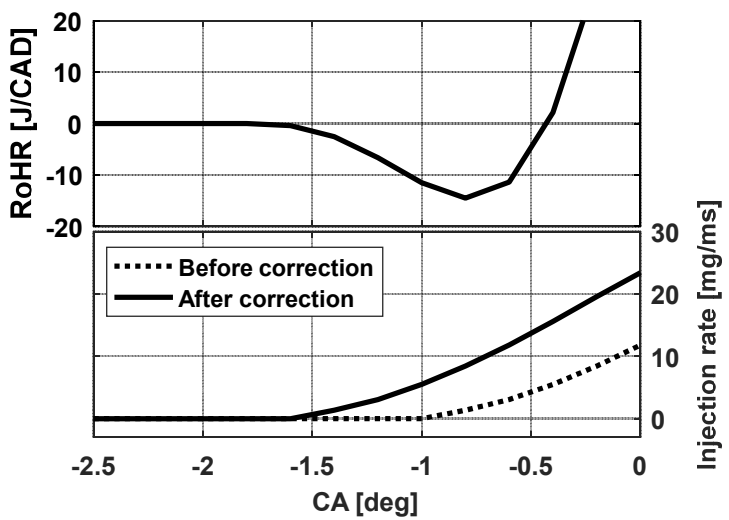

Figure 5. Injection rate signal before and after the delay compensation procedure.

The injection rate for a four-injection strategy estimated using the procedure described in the "Injection Rate Measurement" subsection is presented in Figure 6. This case will later be referred to as the " 4 inj" case.

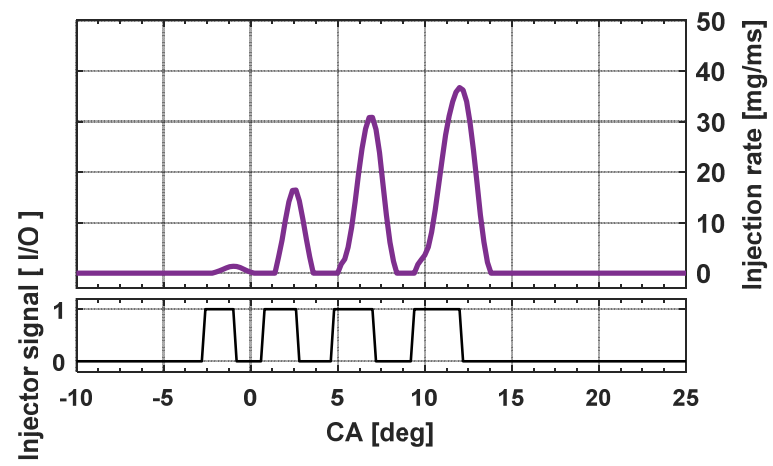

Figure 6. Injector signal and the resulting injection rate for the "4 inj" case.

These results show that at 150 bar PCP and 10-11 bar IMEPg, the injection strategy required to achieve the isobaric combustion cycle does not lead to the merging of injections, as was assumed in [6]. However, the required shot-to-shot separation between the third and the fourth injections is only $1 \mathrm{CAD}$, which is shorter than that recommended by the injector manufacturer (1.44 CAD at 1200 RPM) [17]. This led to instabilities in the system, as was described in [6].

Figure 7 shows the injection rate for the five-injection strategy, later referred to as the " 5 inj" case. From this plot the merger of the fourth and the fifth injections can be observed. 


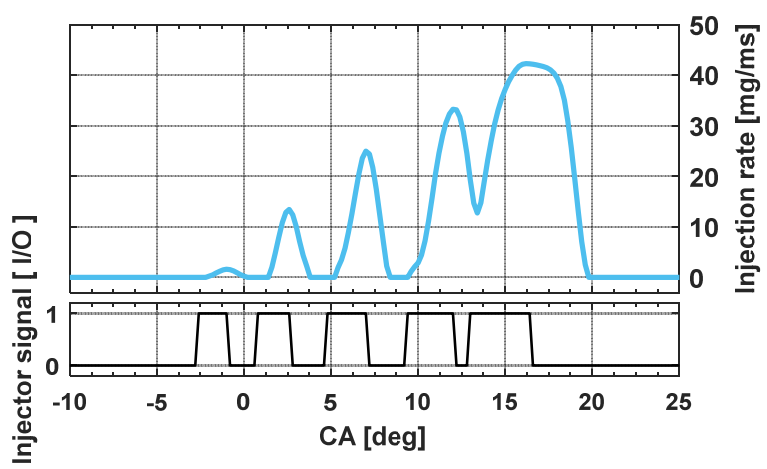

Figure 7. Injector signal and the resulting injection rate for the " 5 inj" case.

It should be noted that the first injections could not be captured with our setup, even though the heat release from it is clearly visible in Figure 8 and Figure 16. The rate could not be measured most likely because of the negligible momentum of the spray. This conclusion will also be supported by the pollutants formation data, which is presented in the next sub-section. A further investigation of this phenomena is planned to be performed in an optical engine. However, for the illustration purposes, in this study the injection rate for the first injection was reconstructed based on:

- Estimation of the fuel amount from the heat release trace

- Assumption of the same $\dot{m}_{f}$ distribution (rate shape) as in the second injection

- Hydraulic delay measured by increasing the sensor amplification gain.

\section{ISOBARIC COMBUSTION AT DIFFERENT ENGINE LOADS}

Load sweep with isobaric combustion is performed by increasing the number of injections with increasing load as well as extending the duration of injection when required. Table 2 presents the number of injections, the measured fuel mean effective pressure (FuelMEP), air-fuel equivalence ratio $(\lambda)$, and gross indicated mean effective pressure (IMEPg). The injection timings and durations are illustrated in Figure 8.

Table 2. Test conditions used in the study of the effect of engine load on the isobaric combustion cycle.

\begin{tabular}{|l|l|l|l|}
\hline $\begin{array}{c}\text { Number of } \\
\text { injections }\end{array}$ & $\begin{array}{c}\text { FuelMEP } \\
{[\mathrm{bar}]}\end{array}$ & $\begin{array}{c}\text { Air-fuel } \\
\text { equivalence } \\
\text { ratio }(\lambda)[-]\end{array}$ & $\begin{array}{c}\text { IMEPg } \\
{[\mathrm{bar}]}\end{array}$ \\
\hline 2 inj & 4.2 & 19.04 & 1.3 \\
\hline 3 inj & 13.0 & 6.41 & 5.9 \\
\hline 4 inj & 23.7 & 3.55 & 11.1 \\
\hline 4 inj (long) & 32.2 & 2.63 & 14.7 \\
\hline 5 inj & 44.8 & 1.86 & 19.7 \\
\hline
\end{tabular}

Isobaric combustion is possible to realize at a wide range of loads. As seen from Figure 8 , different loads can be achieved by varying the number of injections and, in some case, injection duration. The engine load was swept from 0 up to almost 20 bar IMEPg (Table 2) by increasing the number of injections from 1 to 5 . Moreover, in a limited range, it is possible to increase the load by prolonging the duration of the last injection. This can be observed in the " 4 inj (long)" case in Figure 8. However, this applies only to late injections (after 10 CAD ATDC). Doing so to earlier injections leads to the in-cylinder pressures higher than the peak motored pressure.

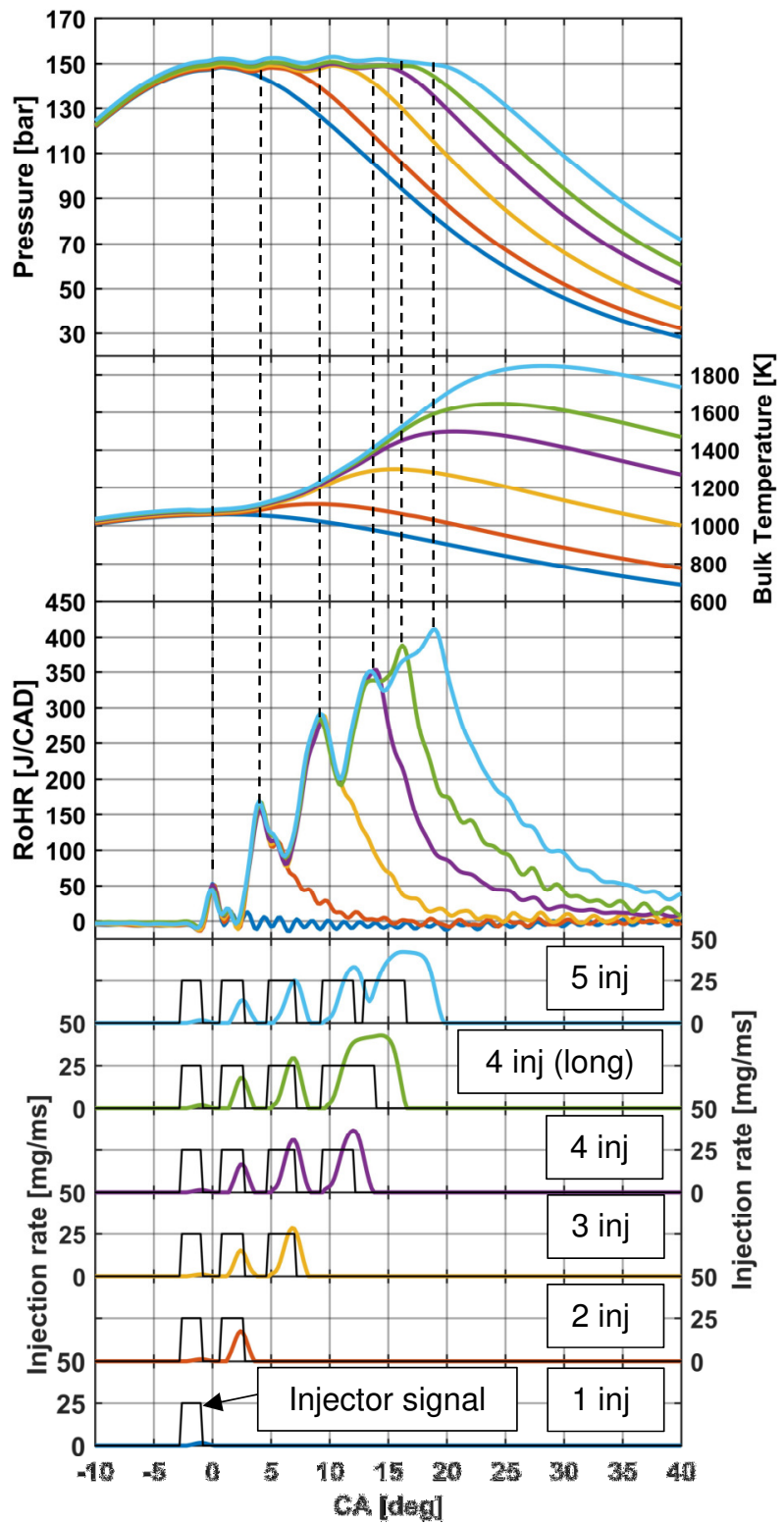

Figure 8. Injector signal, the resultant injection rate, rate of heat release (RoHR), and the in-cylinder bulk temperature and pressure for the load sweep with isobaric combustion.

The isobaric combustion is primarily governed by diffusion flame, having negligible premixed part. It can be seen from Figure 8 that each injection has a corresponding local maxima in the RoHR trace. These peaks correspond to the end of each injection. However, this is not as distinctly pronounced with the 
fourth and fifth pulses. Moreover, the RoHR trace of the five-injection case follows that of the case with a prolonged fourth injection (" $4 \mathrm{inj}$ (long)") near the global maxima (final peak). This is a consequence of the merged fourth and fifth injection, as can also be observed from in the injection rate. This also suggests that higher engine loads require injections to be phased closer to one another, in some cases resulting in their merger.

Another important observation that can be made is that later injections have distinctly lower rise of RoHR. In the isobaric combustion concept the pressure is kept constant by carefully controlling the RoHR. The energy has to be added to the working gas at exactly the same rate as it is extracted from the gas and converted into the work by the moving piston (or lost via heat transfer). When the RoHR level is too high the addition of fuel is stopped, and a certain separation between injections is implemented to keep the average RoHR within the correct range.

However, as seen in Figure 8, the RoHR rise becomes slower the later the injection is, even though the amount of fuel per injection is larger. This trend is illustrated in Figure 9. The RoHR rise from each injection is quantified as the derivative of the RoHR with respect to CAD $(d(R o H R) / d(C A D))$ over the range corresponding to each injection. The values are reported in Table 3. The slower rise of RoHR also led to the need to phase later injections closer to one another.

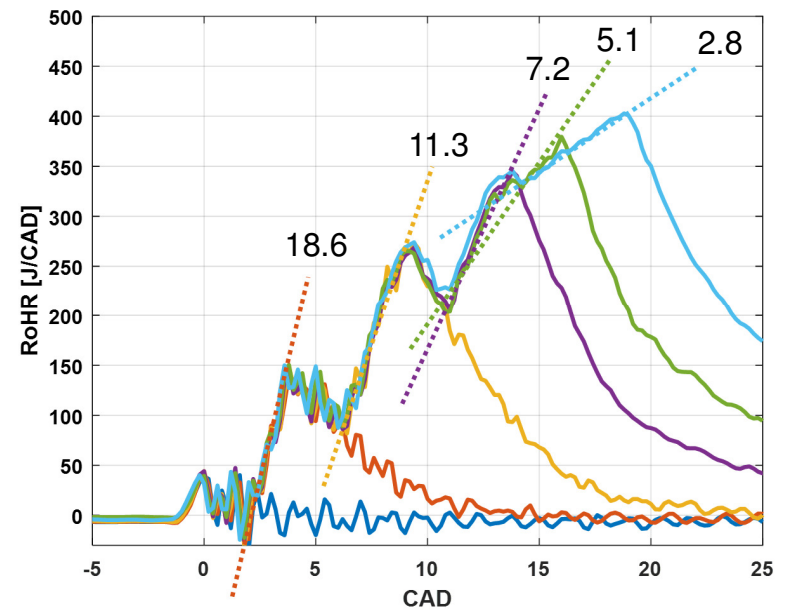

Figure 9. RoHR and its rise rate in [J/CAD $\left.{ }^{2}\right]$ corresponding to each injection.
Table 3. RoHR rise rate over the crank angle range and injected mass corresponding to each injection.

\begin{tabular}{|l|c|c|c|}
\hline $\begin{array}{c}\text { Injection } \\
\text { number }\end{array}$ & $\begin{array}{c}\text { Injected } \\
\text { fuel } \\
\text { mass } \\
{[\mathrm{mg}]}\end{array}$ & $\begin{array}{c}\text { Crank } \\
\text { angle } \\
\text { range } \\
{[\mathrm{CAD}]}\end{array}$ & $\begin{array}{c}\frac{d(\text { RoHR })}{d(\mathrm{CAD})} \\
{\left[\mathrm{JCAD}^{2}\right]}\end{array}$ \\
\hline $1^{\text {st }}$ inj. & 1.5 & - & - \\
\hline $2^{\text {nd }}$ inj. & 12.2 & $2.2-3.6$ & 18.6 \\
\hline $3^{\text {rd }}$ inj. & 28.3 & $6.6-9.4$ & 11.3 \\
\hline $4^{\text {th }}$ inj. & 55.7 & $11.2-14.0$ & 7.2 \\
\hline $4^{\text {th }}$ inj. (long) & 141.9 & $11.2-16.2$ & 5.1 \\
\hline $\begin{array}{l}4^{\text {th }}+5^{\text {th }} \\
\text { injections }\end{array}$ & 193.0 & $14.2-19.0$ & 2.8 \\
\hline
\end{tabular}

The main conclusion of this discussion is that late injections struggle to keep pressure constant during combustion both owing to slower kinetics and the demand of higher rate of energy addition later in the cycle due to faster expansion and heat losses. At loads above 20-25 bar IMEPg, the pressure trace is expected to start reducing before the end of the injection, leading to a potential decrease in the area under the pressure trace and, consequently, reduction in efficiency.

Figure 10 presents the gross indicated efficiency as a function of the engine load. The peak efficiency of $47 \%$ is achieved at 11 bar IMEPg with four injections. The red error bars indicate the uncertainty in the estimation of the amount of fuel injected per cycle within the confidence interval of $95 \%$.

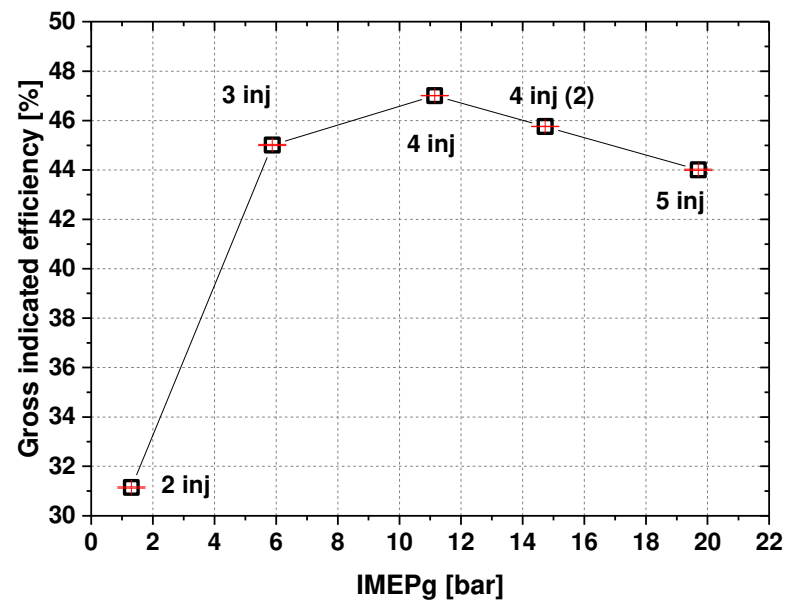

Figure 10. Gross indicated efficiency of the isobaric combustion cycles as a function of the engine load.

Figure 11 shows the engine energy distribution at different loads. The low-load cases have lower gross indicated efficiency owing to a high fraction of fuel energy lost to heat transfer. Higher-load cases (1520 bar IMEPg), however, reduce in efficiency due to an increase in the exhaust losses. This can be explained 
by a lower effective expansion ratio as a result of a late heat addition process. The 11.1 bar IMEPg case seems to be in the optimum point of the heat transfer and exhaust losses trade-off.

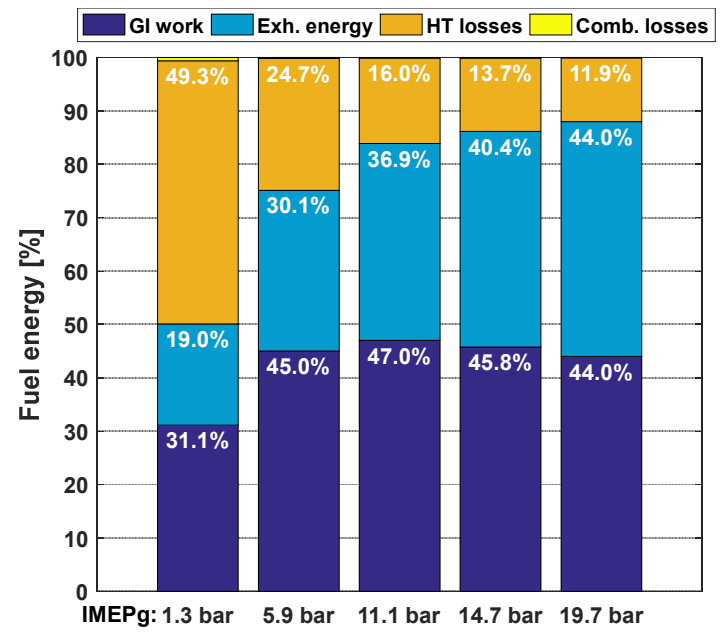

Figure 11. Gross indicated work (GI work), exhaust energy, heat transfer (HT) losses, and combustion losses as a fraction of the total fuel energy.

It should be noted, that the DCEE concept, for which the isobaric combustion cycle was proven most suitable, is capable of recovering the exhaust energy of the combustor unit by performing the second stage of expansion in the expander unit. The DCEE system efficiency is not necessarily going to peak at 11 bar IMEPg. The complete system simulations must be performed using the data obtained from this and the previous study in order to predict the optimum load point of the DCEE concept.

\section{Emissions}

The emissions are reported both as a concentration of the pollutant in the exhaust gas and as specific emissions. The specific emissions were calculated by normalizing the pollutant concentration by the gross indicated work in [kWhi] ("i" denotes "indicated"). The purpose of the concentration plots is to illustrate the dynamics of the pollutant formation and oxidation during the multiple injection sequence. Since the number of injections was increased progressively and the emissions were recorded at each step, it is possible to demonstrate the role of each injection in the pollutant formation and oxidation.

From the concentration plot in Figure 9 (bottom) it can be concluded that a significant amount of soot is formed during the first injection due to both relatively low combustion temperatures and very low spray momentum, as discussed in the "Injection Rate" subsection. The low spray momentum leads to low mixing rates and locally rich zones, which promote the formation of soot. With subsequent injections, the soot oxidation prevails owing to higher mixing rates and higher temperatures, leading to a gradual decrease in the soot emissions. The last (fifth) injection seems to produce more soot than it can oxidize. This is the consequence of two factors: 1 . Late combustion and hence the associated lower combustion temperatures,
2. Lower $\lambda$, which means reduced availability of oxygen. The specific soot emissions, on the other hand, consistently reduce with higher load (Figure 12, top plot).
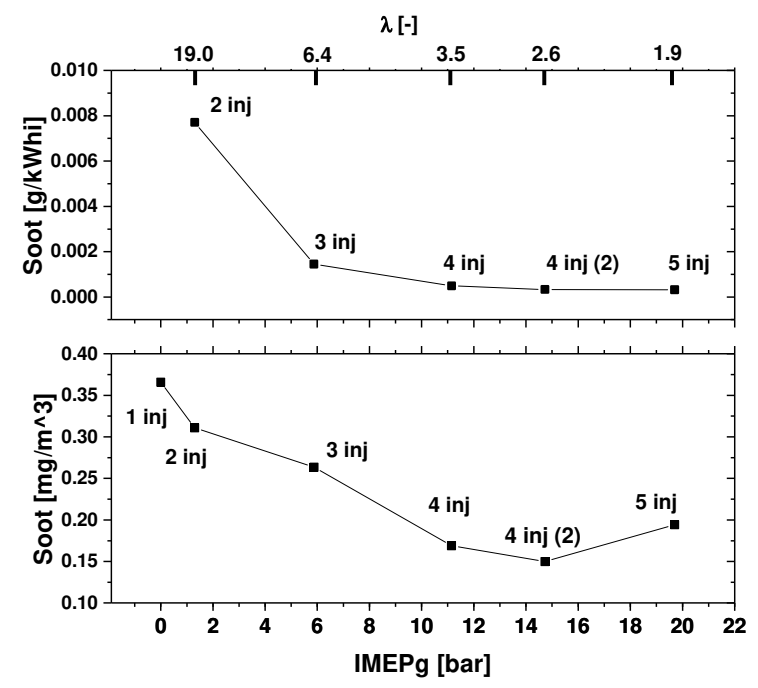

Figure 12. Exhaust soot concentration (bottom) and specific soot emissions (top).

As seen in the concentration plot of Figure 13 (bottom), the exhaust NOx concentration exhibits a linear trend with engine load (and injection number). The contribution of each injection to the NOx formation is fairly equal, even though the amount of fuel per injection is different (Table 3 ). The increase in the NOx concentration is the result of a larger high-temperature zone, as well as a longer residence time of combustion products at high temperatures. On the other hand, the normalized NOx emissions reduce at higher loads, following the trend in soot emissions.

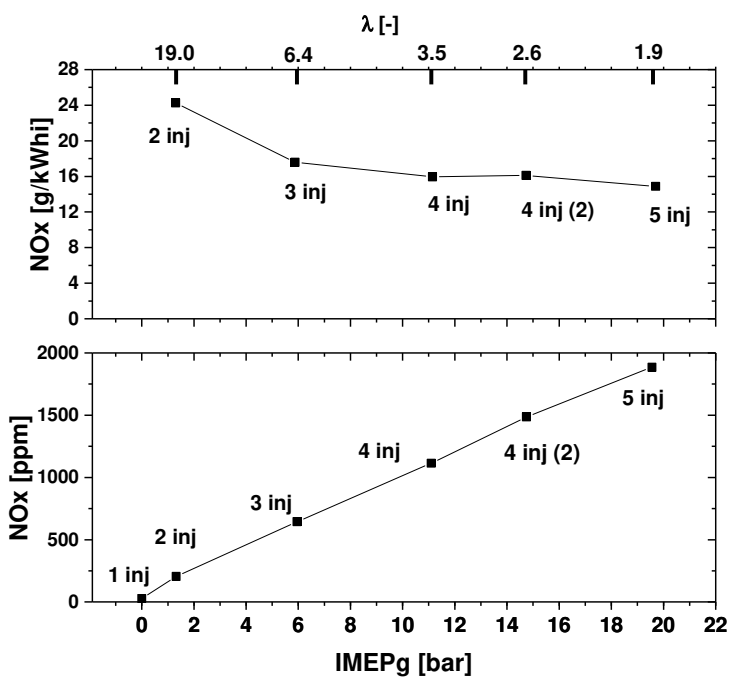

Figure 13. Exhaust NOx concentration (bottom) and specific NOx emissions (top).

Figure 14 (bottom) shows that unburned hydrocarbons (UHC) are the highest with the first injection, again, owing to relatively low combustion temperatures; then they are burned off during the second and the third injections. However, from the fourth injection onwards UHC concentration increases again. Figure 14 (top) 
shows that specific UHC emissions, again, reduce at higher load points.
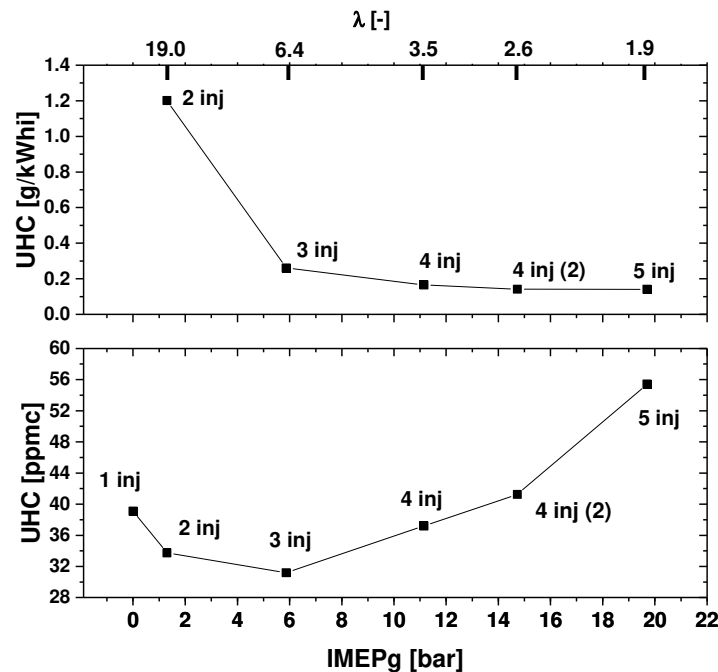

Figure 14. Exhaust UHC concentration (bottom) and specific UHC emissions (top).

From Figure 15 (bottom) it can be concluded that the first two injections generate most of the $\mathrm{CO}$ due to relatively low combustion temperatures. As seen from Figure 14, these temperatures are more favorable for $\mathrm{UHC}$ production, rather than $\mathrm{CO}$. The second injection generates higher temperatures (hence lower UHC), but not high enough to fully oxidize the fuel and produce more $\mathrm{CO}_{2}$, leading to the increase in the $\mathrm{CO}$ production. The subsequent injections lead to temperatures high enough for a better $\mathrm{CO}$ oxidation. The fifth injection, however, generates more $\mathrm{CO}$, again, owing to lower local temperatures associated with late combustion and reduced availability of oxygen. The specific CO emissions, once again, consistently reduce with higher load.
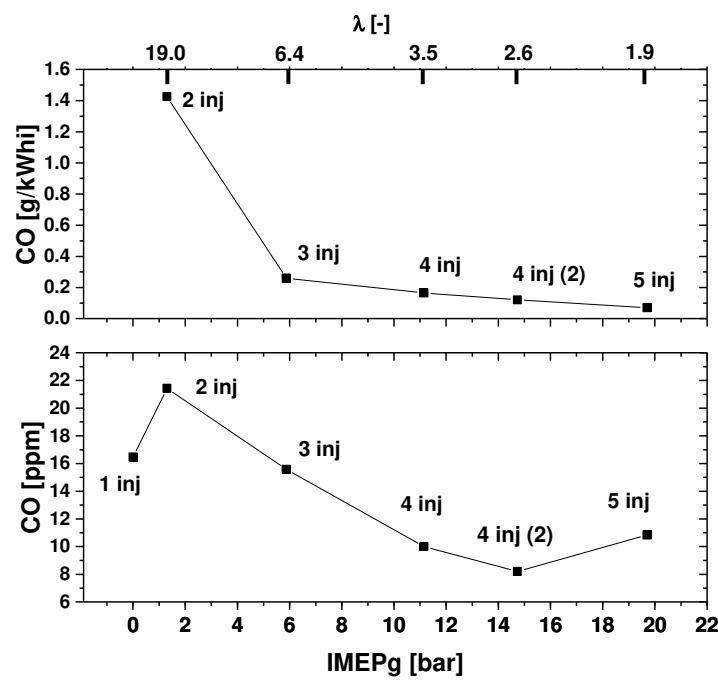

Figure 15. Exhaust $\mathrm{CO}$ concentration (bottom) and specific $\mathrm{CO}$ emissions (top).

A detailed data of the local temperatures and equivalence ratio is necessary to better understand the dynamics of the pollutants formation. This data can be obtained by performing CFD simulations.

\section{EFFECT OF INJECTION STRATEGY}

The complexity of injection strategy is varied by lowering the number of injection events from four down to one. This requires changes in injection duration to maintain a constant load. Table 4 lists the different injection strategies investigated in this study.

Table 4. Test conditions used in the study of the effect of different injection strategies on the isobaric combustion cycle.

\begin{tabular}{|l|l|l|l|}
\hline $\begin{array}{c}\text { Number of } \\
\text { injections }\end{array}$ & $\begin{array}{c}\text { FuelMEP } \\
{[\text { bar] }}\end{array}$ & $\begin{array}{c}\text { Air-fuel } \\
\text { equivalence } \\
\text { ratio }(\lambda)[-]\end{array}$ & $\begin{array}{c}\text { IMEPg } \\
{[\mathrm{bar}]}\end{array}$ \\
\hline 1 inj. & 23.8 & 3.55 & 11.1 \\
\hline 2 inj. & 24.1 & 3.58 & 11.2 \\
\hline 3 inj. & 23.7 & 3.62 & 11.2 \\
\hline 4 inj. & 23.7 & 3.55 & 11.1 \\
\hline
\end{tabular}

Isobaric combustion cycle of different qualities achieved using different injection strategies is studied at the optimum load point of around $11 \mathrm{bar}$ IMEPg. The air-fuel equivalence ratio is kept approximately constant, leading to similar IMEPg values for all cases. The injector signal, injection rate, RoHR and pressure trace for four different strategies are presented in Figure 16 and compared with a CDC case.

Generally, the lower the number of injections used the wavier the pressure trace becomes. An extreme case is the single-injection strategy where the cycle is not isobaric, per se, but is better characterized as a restricted pressure cycle. Overall, the differences between the cases with four, three, and two injections are minor. Gross indicated efficiency varies slightly, as seen from Figure 17. With fewer injections exhaust energy undergoes a slight increase, whereas the heat transfer losses first reduce with three injections, then increase again with two injections (Figure 18). A more significant drop in efficiency is observed if only one injection is used. This is accompanied by a further increase in exhaust energy and a drop in the heat transfer losses. 


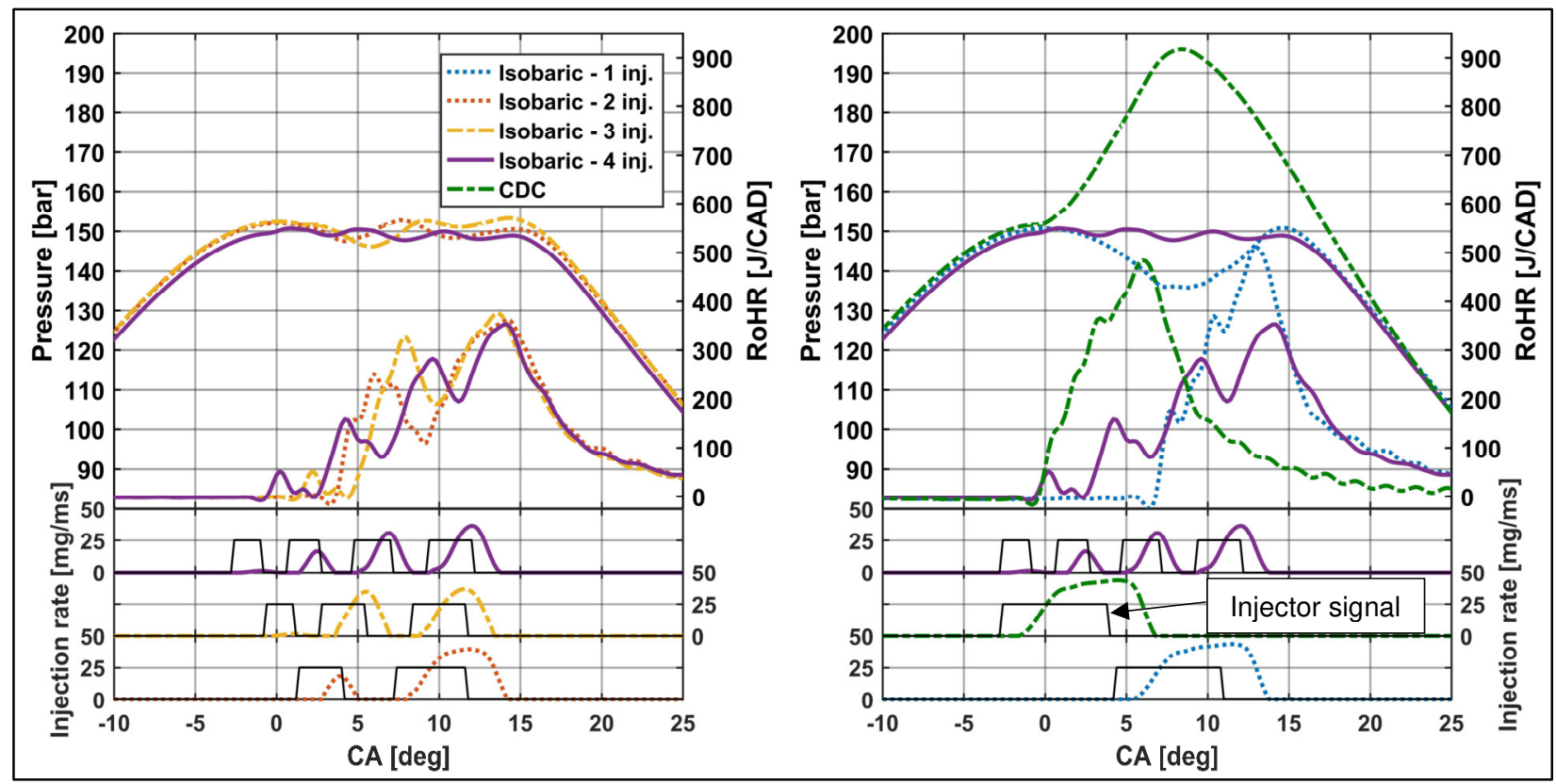

Figure 16. Different injection strategies at the constant equivalence ratio of 3.6.

The gradual increase in exhaust energy with fewer injections can be explained by a later combustion phasing and, consecutively, a lower effective expansion ratio. The heat transfer losses, however, exhibit more complex behavior. Looking at the bulk temperatures one can see that peak temperatures are similar for all isobaric combustion cases (Figure 19). However, during the first 12 CAD after TDC the bulk temperatures vary more significantly, which is a result of different SOI times. It is known that the convection heat transfer coefficient is the highest during the fuel injection and combustion processes, and the differences in temperatures during that period have a stronger impact on heat transfer. The estimated heat flux from 1-D simulations is presented in Appendix A. Moreover, depending on the injection strategy implemented, the high temperature zones might have a more intimate contact with the combustion chamber walls, which affects heat transfer losses substantially.

Coefficient of variation (CoV) of IMEP quantifies the cyclic variability in indicated work per cycle, and it is used to characterize cyclic combustion variations. In this study it is estimated by dividing the standard deviation of IMEPg by the average of IMEPg over 1200 cycles for each case. Figure 17 demonstrates that the CoV for the one-, two-, and three-injection cases is fairly similar and comparable with the values for CDC. However, when the four-injection strategy is implemented the CoV increased up to almost $2 \%$. This level of CoV is still acceptable as the degradation in vehicle drivability is usually noticed when CoV exceeds $3-5 \%$.

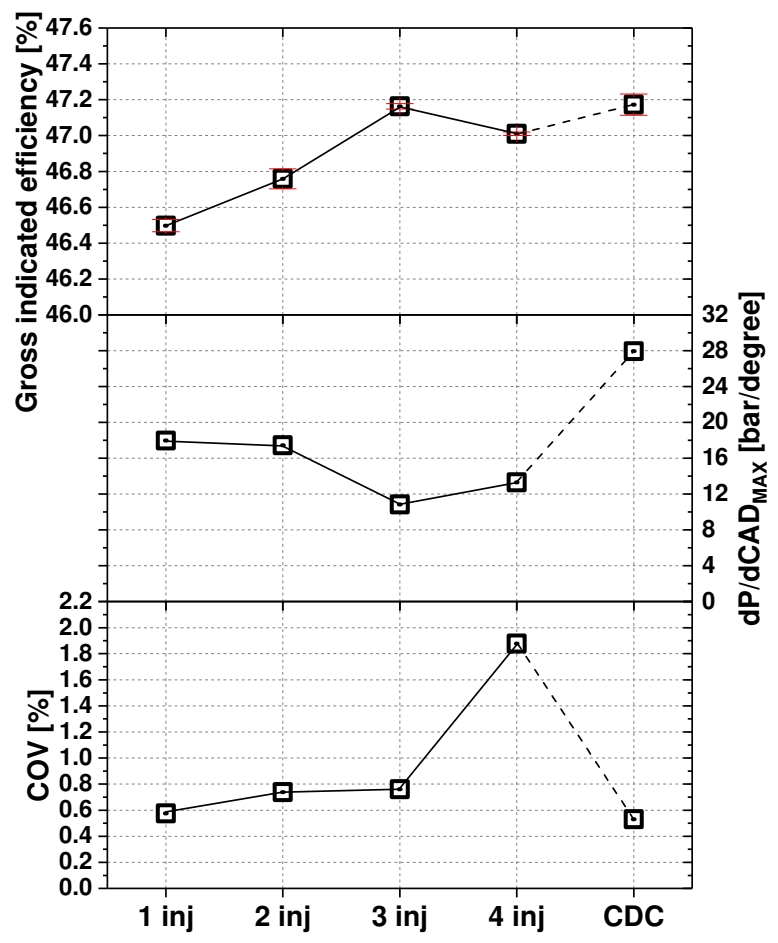

Figure 17. Gross indicated efficiency, maximum pressure rise rate, and the coefficient of variation of IMEP as a function of the number of injections in the isobaric combustion cycles. 


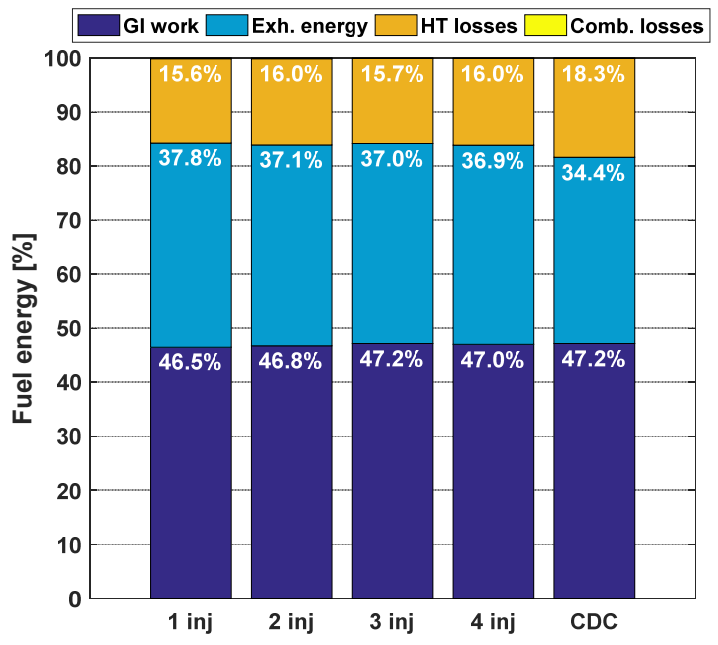

Figure 18. Gross indicated work (GI work), exhaust energy, heat transfer $(\mathrm{HT})$ losses, and combustion losses as a fraction of the total fuel energy.

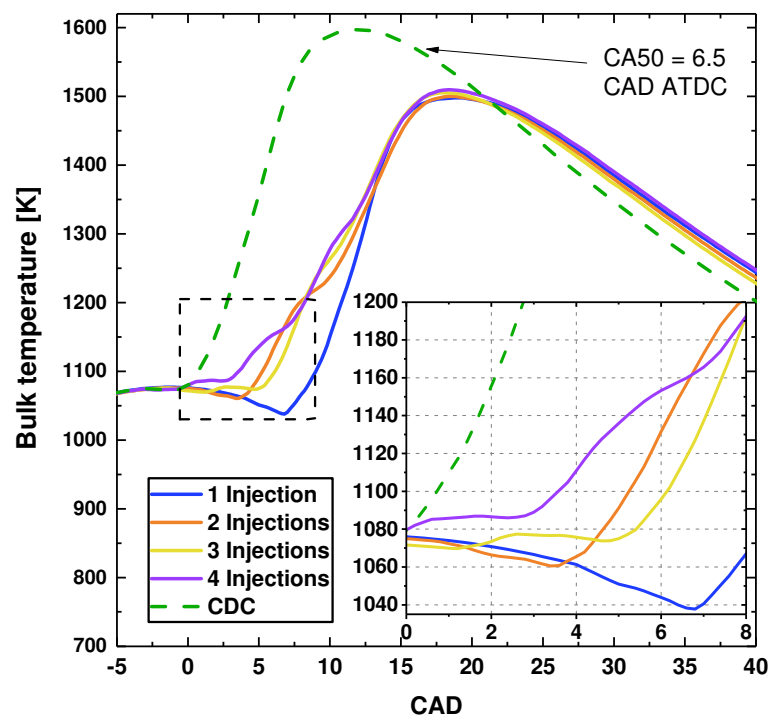

Figure 19. In-cylinder bulk temperature estimated using 1-D simulation.

The combustion noise in this study is qualitatively estimated by calculating the maximum pressure rise rate as it is typically the dominant parameter affecting engine noise. The pressure trace is first differentiated, then the maximum value for each case is taken and compared in Figure 17 (middle plot). As can be seen from the plot, the maximum rate of pressure rise is approximately two times lower for isobaric combustion compared to the CDC, which is expected to have a positive impact on noise emissions. It should be noted that the maximum pressure rise rate for isobaric combustion turned out to be larger than initially anticipated. This is the result of high-frequency pressure oscillations that were captured by the pressure sensor during the combustion process. This phenomenon is planned to be investigated in details in a future study and the in-cylinder pressure data to be compared to the engine noise data from acoustic measurements.

Figure 20 shows the relation between the phasing of the isobaric combustion and the gross indicated efficiency at the same equivalence ratio. The combustion phasing is represented by the CAD at which $50 \%$ of the heat of combustion is released (CA50). The efficiency exhibits an inverse relation with the combustion phasing within the small range of variation of CA50 that can be realized using different injection strategies at the same load point under the constraints of the constant-pressure heat addition.

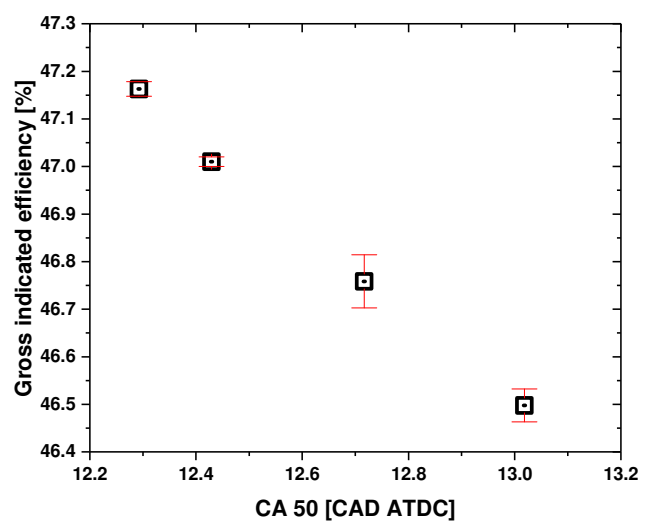

Figure 20. Gross indicated efficiency of the isobaric combustion cycle as a function of the CA50.

Overall, it can be concluded that the number of injections used to achieve the isobaric combustion cycle does not have a significant impact on the gross indicated efficiency and energy flow in the engine, as long as more than one injection is used.

Comparing the isobaric cycles (2-4 injections) with the CDC cycle (Figure 17 and 18), one can see that they have approximately same indicated efficiency, however, the energy distribution differs quite significantly. The isobaric combustion cycle has over 2 percent-points lower fraction of energy lost as HT losses, which, instead, leaves the cylinder as exhaust energy. This is the same trend observed in the previous study [6], and, once again, shows the advantage of the isobaric cycle over the CDC cycle for the use in the DCEE concept. As discussed previously, the exhaust energy, unlike the HT losses, can be used to generate more work in the expander unit, hence, increasing the overall efficiency of the system. Moreover, since the PCP in the isobaric cycle is much lower than in the CDC cycle (150 bar vs. 196 bar, respectively), the combustor unit can be optimized in terms of mechanical efficiency for lower PCPs, further increasing the brake thermal efficiency of the DCEE.

\section{Emissions}

In this comparison, only the normalized emission values are presented because the trends in the concentration plots would be very similar as a result of the same load point for all cases.

As seen from Figure 21, the emissions of soot do not vary significantly with the varying number of injections at the same load point (and same lambda), even though they tend to reduce slightly with higher number of injections, most likely owing to a better mixing when the same amount of fuel is distributed over a higher number of injections. The soot emissions from the 
CDC are also fairly similar to those of the isobaric cycles.

The emissions of NOx are also nearly constant for all four isobaric combustion cycles. However, isobaric combustion generates nearly two times lower NOx emissions compared to the CDC owing to much lower temperatures (Figure 19).

The unburned hydrocarbon emissions are slightly higher with lower number of injections and fairly similar to those from CDC. The CO emissions, on the other hand, are higher when more injections are used.

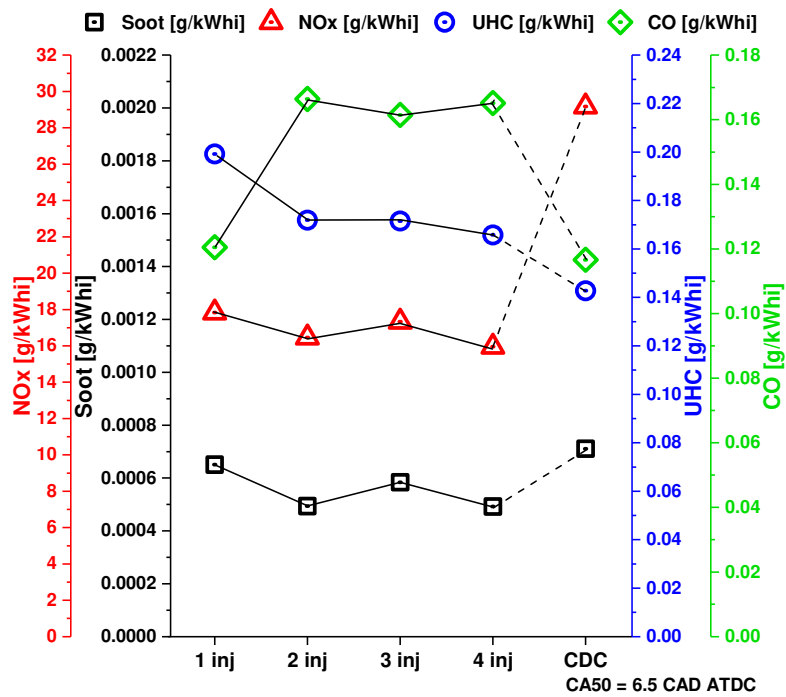

Figure 21. Emissions from different injection strategies at the same load point and lambda.

\section{CONCLUSIONS}

1. The isobaric combustion cycle is possible to achieve at high engine loads by increasing the number of injections and the duration of the late injections.

2. The highest efficiency was achieved with 4 injections at 11 bar IMEPg. The efficiency reduced at lower loads due to higher heat transfer losses, and at higher loads - due to increased exhaust losses.

3. Specific emissions consistently reduce with the increase in engine load at lean conditions.

4. Soot, $\mathrm{CO}$ and UHC are formed during the first injection, then oxidized during the subsequent injections. Soot, $\mathrm{CO}$ and UHC formation rate increases again during the late injections. NOx formation is only a function of the total injection duration.

5. Alteration of the injection strategy does not have a significant impact on the efficiency, energy distribution and emissions of the isobaric combustion cycle as long as more than one injection is used.
6. At high peak motoring pressures, isobaric combustion cycle is capable of achieving efficiencies equal to those of the CDC cycle. However, having much lower peak cylinder pressures, lower heat transfer losses, and higher exhaust enthalpy, it is expected to enable the DCEE to achieve higher break thermal efficiency.

\section{REFERENCES}

1. Lam, N., Tuner, M., Tunestal, P., Andersson, A. et al., "Double Compression Expansion Engine Concepts: A Path to High Efficiency," SAE Int. J. Engines 8(4):1562-1578, 2015, https://doi.org/10.4271/2015-01-1260.

2. Lam, Nhut, Arne Andersson, and Per Tunestal. "Double Compression Expansion Engine Concepts: Efficiency Analysis over a Load Range." SAE Technical Papers 2018 (2018).

3. Bhavani Shankar, V., Lam, N., Andersson, A., and Johansson, B., "Optimum Heat Release Rates for a Double Compression Expansion (DCEE) Engine," SAE Technical Paper 2017-01-0636, 2017, doi:10.4271/2017-01-0636.

4. Shankar, Bhavani, Vijai Shankar, Bengt Johansson, and Arne Andersson. "Double Compression Expansion Engine: A Parametric Study on a High-Efficiency Engine Concept." SAE Technical Paper Series (2018).

5. Okamoto, T. and Uchida, N., "New Concept for Overcoming the Trade-Off between Thermal Efficiency, Each Loss and Exhaust Emissions in a Heavy Duty Diesel Engine," SAE Int. J. Engines 9(2):2016, doi:10.4271/2016-01-0729.

6. Babayev, R., Ben-Houidi, M., Andersson, A., Johansson, B., "Isobaric Combustion: A Potential Path to High Efficiency, in Combination with the Double Compression Expansion Engine (DCEE) Concept", SAE Technical Paper 2019-01-0085, 2019.

7. Reducing Particulate and NOx Emissions by Using Multiple Injections in a Heavy Duty D.I. Diesel Engine, T. C. Tow, D. A. Pierpont and R. D. Reitz, SAE Transactions, Vol. 103, Section 3: JOURNAL OF ENGINES (1994), pp. 1403-1417] [Simultaneous Reduction of NOx and Particulate Emissions by Using Multiple Injections in a Small Diesel Engine, S. Kevin Chen, SAE Transactions, Vol. 109, SECTION 3: JOURNAL OF ENGINES (2000), pp. 2127-2136.

8. Influence of Multiple Injection Strategies on Emissions, Combustion Noise and BSFC of a DI Common Rail Diesel Engine, M. Badami, F. Mallamo, F. Millo and E. E. Rossi, SAE Transactions, Vol. 111, Section 3: JOURNAL OF ENGINES (2002), pp. 1118-1129.

9. Influence of the Post-Injection Pattern on Performance, Soot and NOx Emissions in a HD Diesel Engine, SAE 2002-01-0502.

10. Influence of Pre- and Post-Injection on the Performance and Pollutant Emissions in a HD Diesel Engine, SAE 2001-01-0526. 
11. Exploring the Use of Multiple Injectors and Split Injection to Reduce DI Diesel Engine Emissions, A. Uludogan, J. Xin, and R. D. Reitz, SAE 962058.

12. Using spray momentum flux measurements to understand the influence of diesel nozzle geometry on spray characteristics, R. Payri, J.M. Garcia, F.J. Salvador, J. Gimeno, fuel 2005.

13. Hydraulic characterization of high-pressure gasoline multi-hole injector Balaji Mohan, Jianguo $\mathrm{Du}$, Jaeheon Sim, William L. Roberts Flow Measurement and Instrumentation 64 (2018) 133141.

14. Desantes, José M., J. Javier López, Marcos Carreres, and Darío López-Pintor. "Characterization and prediction of the discharge coefficient of non-cavitating diesel injection nozzles." Fuel 184 (2016): 371-381.

15. https://www.gtisoft.com/gt-suiteapplications/propulsion-systems/gt-power-enginesimulation-software/

16. Dernotte, J., Dec, J., and Ji, C., "Energy Distribution Analysis in Boosted HCCl-like / LTGC Engines - Understanding the Trade Offs to Maximize the Thermal Efficiency," SAE Int. J. Engines 8(3):2015, doi:10.4271/2015-01-0824.

17. Meek, G., Williams, R., Thornton, D., Knapp, P. et al., "F2E - Ultra High Pressure Distributed Pump Common Rail System," SAE Technical Paper 2014-01-1440, 2014, doi:10.4271/2014-01-1440.

\section{CONTACT DETAILS}

Rafig Babayev

Clean Combustion Research Center (CCRC)

King Abdullah University of Science and Technology (KAUST)

Building 5, 4204-WS10, Thuwal 23955-6900,

Saudi Arabia

rafig.babayev@kaust.edu.sa

rafik.babayev95@gmail.com

+966560249272

\section{DEFINITIONS, ACRONYMS, ABBREVIATIONS}

ATDC: after top dead center

CA50: crank angle at which $50 \%$ of the total heat of combustion has been released.

CAD: crank angle degree.

CDC: conventional diesel combustion

CFD: computational fluid dynamics

Cl: compression ignition

CO: carbon monoxide

$\mathrm{CO}_{2}$ : carbon dioxide

COV: coefficient of variation
DCEE: double compressions expansion engine

EGR: exhaust gas recirculation

FuelMEP: fuel mean effective pressure

GI: gross indicated

HT: heat transfer

IMEPg: gross indicated mean effective pressure

NOx: oxides of nitrogen

PCP: peak cylinder pressure

PMP: peak motoring pressure

RoHR: rate of heat release

RPM: revolutions per minute

SOHC: single overhead cam

UHC: unburned hydrocarbons

\section{APPENDIX}

\section{APPENDIX A}

Heat flux to the cylinder walls in $\left[\mathrm{kW} / \mathrm{m}^{2}\right]$.

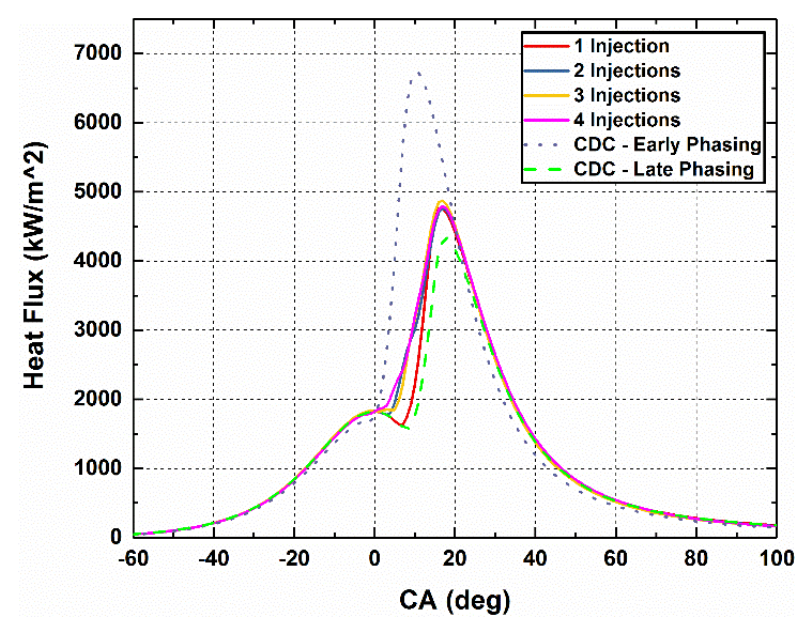

